\title{
ANARQUISTAS: CRIAÇÃO CULTURAL, INVENÇÃO PEDAGÓGICA
}

\author{
Doris ACCIOLY E SILVA*
}

\begin{abstract}
RESUMO: O artigo resgata dimensões das práticas culturais e pedagógicas anarquistas que foram referência para a experiência brasileira das Escolas Modernas, no início do século xx (1912). Baseando-se em pesquisas bibliográficas realizadas por inúmeros estudiosos no Brasil e na Espanha, o presente ensaio procura mostrar a inseparabilidade cultura-educação nas concepções e nas práticas anarquistas. Tal especificidade do movimento ácrata configura sua visão educacional, na escola ou fora dela, como campo de apropriação da cultura e instrumento de libertação social.
\end{abstract}

Palavras-chave: Cultura. Educação. Anarquistas. Memória. Libertação social.

\section{ANARCHISTS: CULTURAL CREATION, PEDAGOGICAL INVENTION}

ABSTRACT: This paper explores dimensions of the anarchist cultural and pedagogical practices that served as a reference for the Brazilian experience of Modern Schools, in the beginning of the $20^{\text {th }}$ century (1912). Based on bibliographical research accomplished by innumerable scholars in Brazil and Spain, it tries to point out the inseparability of culture and education in the anarchist conceptions and practices. Such a specificity configures the educational view-point of anarchists, inside and outside school, as a field of appropriation of culture and as an instrument of social liberation.

Key words: Culture. Education. Anarchists. Memory. Social liberation.

\section{ANARChistes: créAtion CUlturelle, INVENTION PÉdAgogiQue}

RÉSUMÉ: Cet article récupère les dimensions des pratiques culturelles et pédagogiques anarchistes qui ont servi de référence à l'expérience brésilienne des Écoles modernes, au début du XXe siècle (1912). Sur la base de recherches bibliographiques réalisées par de nombreux spécialistes au Brésil et en Espagne, le présent essai cherche à montrer l'inséparabilité cultureéducation dans les conceptions et les pratiques anarchistes. Cette spécificité du mouvement «acrate » sous-tend sa vision éducationnelle, à l'école ou hors d'elle, comme champ d'appropriation de la culture et instrument de libération sociale.

Mots-clefs: Culture. Éducation. Anarchistes. Mémoire. Libération sociale. 
$\mathrm{A}$ finalidade deste artigo é examinar aspectos das práticas e teorias ácratas no campo cultural e educacional anteriores e coetâneas à experiência das Escolas Modernas no Brasil, aprofundando assim a compreensão da atmosfera político-cultural e das raízes históricas de tal experiência. ${ }^{1}$

O solo originário da reflexão aqui desenvolvida é a tradição anarquista européia, principalmente a de países como Espanha, Itália e Portugal, de onde veio grande parte dos imigrantes responsáveis, no Brasil, em outros países da América Latina e nos Estados Unidos, pela expansão do anarcosindicalismo e pela criação, no Novo Mundo, das expressões artístico-culturais e pedagógicas inerentes ao movimento anárquico desde suas origens. $\mathrm{O}$ anarquismo, mesmo considerando sua pluralidade de tendências, produziu em sua história experiências pedagógico-culturais inovadoras. Até hoje elas constituem fonte de inspiração para educadores e movimentos sociais que buscam alternativas à educação estatal ou privada e aos métodos convencionais de ensino-aprendizagem.

Um aspecto fundamental do movimento libertário é a recusa incondicional de qualquer tipo de organização política e social baseada na coação, ao lado do desejo e da luta por uma sociedade em que a ordem, a liberdade e a igualdade coincidam. Para atingir tais objetivos, os anarquistas, pelo menos nas correntes majoritárias, baseadas no mutualismo, no cooperativismo e no anarco-comunismo, enfatizam sempre a junção entre os fins e os meios na política, sublinhando que não se pode chegar a fins libertários por vias autoritárias.

Para as finalidades deste artigo serão consideradas as seguintes noções de cultura: a de Raymond Williams (2007, p. 120), para quem a cultura é "todo um modo de vida" e não mero reflexo da produção material das sociedades; a de Clifford Geertz (1978), que a vê como o "fundo acumulado de símbolos significantes", de dispositivos simbólico-práticos partilhados de controle do comportamento,

(...) não apenas simples expressões, instrumentalidade ou correlatos de nossa existência biológica, psicológica e social: eles são seus pré-requisitos. Sem os homens certamente não haveria cultura, mas, de forma semelhante e muito significativa, sem cultura não haveria homens. (Geertz, 1978, p. 56-62)

Além dessas noções, aceito a distinção feita por Dulce Whitaker (2006) entre cultura e ideologia, excluindo da primeira os componentes justificadores da opressão e da exploração que caracterizam o âmbito ideológico. Sem tal distinção, aceitam-se todos os horrores em nome das singularidades culturais: “Em suma, cultura é tudo o que nos humaniza. Fenômenos de opressão e dominação pertencem ao plano da ideologia". A autora, contudo, lembra a intersecção entre ambas, 
(...) na medida em que os processos de dominação colhem, da cultura, os traços que facilitam a opressão e os manipulam, encobrindo parte da cultura com sombras de perversidade e provocando o ilusionismo e a fantasmagoria que disfarçam a dominação. (2006, p. 60-61)

Ainda com relação à ideia de cultura, é importante sublinhar sua dimensão política, nas sociedades divididas em classes, castas, estamentos. Nas palavras de Victor Hell (1989, p. 57):

(...) a liberdade não se parece com o fruto que teria sido amadurecido pelo pensamento: ela requer um combate incessante. $\mathrm{O}$ mesmo ocorre com a cultura que não é simplesmente um patrimônio que se tem de salvaguardar e, se possível, aumentar e enriquecer com a consciência tranquila de um administrador. Ela exige também combate.

A concepção de uma cultura das classes trabalhadoras é também carregada de controvérsias. As condições de exploração e dominação a que estão sujeitas em decorrência de sua posição no processo de produção capitalista são um obstáculo à criação de uma cultura proletária. Além disso, adverte Francisco Foot Hardman (2002, p. 305), "a produção industrial capitalista tende a uniformizar os campos do lazer, da habitação, do vestuário e, inclusive, o da língua", o que complica ainda mais a questão. Este último autor, no entanto, aceitando a reflexão de Raymond Williams, sugere que o que pode singularizar uma cultura proletária "são as formas alternativas de se conceber a natureza das relações sociais". Além disso, "a presença cultural das classes subalternas verificar-se-ia também, sempre segundo Williams, em sua contribuição difusa, porém real, à constituição do próprio processo cultural mais abrangente de toda a sociedade". O que procurarei definir no presente artigo é a criação, pelos anarquistas, de uma cultura de resistência e de uma cultura de combate, historicamente concretizadas nas escolas libertárias, na imprensa operária, nos centros de cultura social, no teatro, na poesia e mesmo em obras científicas, como é o caso de Elisée Reclus (1830-1905) e Kropotkin (1842-1921). Constituíram, portanto, um raro momento em que as classes trabalhadoras puderam construir uma reflexão e um conhecimento próprios e indissociáveis das formas de organização de suas lutas. No Brasil, a partir da década de 1970, a pesquisa universitária tem produzido teses fecundas sobre a educação e a cultura ácratas e sobre outros aspectos do anarquismo, temas considerados malditos nas décadas anteriores, devido à hegemonia de uma intelectualidade conservadora de direita ou stalinista. Nas ciências sociais e na história, são exceções ao silêncio trabalhos como o de Aziz Simão (um dos precursores da sociologia do trabalho no Brasil) sobre as origens anarquistas do sindicalismo brasileiro e os de Maurício Tragtenberg sobre o makhnovismo e os marinheiros de Kronstadt, durante a Revolução Russa, escritos entre 1953 e início de 1960 (vide bibliografia). A produção literária ácrata foi acompanhada por vários críticos, a partir do próprio momento em que surgiram na cena brasileira e nas décadas seguintes, como é o caso de José Veríssimo, Nestor Victor, Eduardo Frieiro, Brito Broca, Antonio 
Candido, Fábio Lucas, entre outros. Há sobre tal produção, abrangendo a imprensa, a poesia, o teatro e a educação, trabalhos atuais relevantes de pesquisa, como os de Antonio Arnoni Prado e Francisco Foot Hardman e o de Flávio V. Luizetto. Além destes, é referência obrigatória a vasta obra de Edgar Rodrigues, português radicado há muito no Rio de Janeiro, pesquisador e militante do anarquismo. Estes autores divergem quanto ao valor literário intrínseco de tais obras, o que é decorrência de diferentes visões de mundo, inserções políticas, distanciamento crítico, perspectiva intelectual. Assim, para Flávio Luizetto, o interesse do "episódio literário" anarquista no Brasil prende-se à sua importância para o conhecimento do anarquismo em nosso país para a historiografia das ideias sociais e políticas no Brasil,

(...) especialmente quando esta prosa de ficção é examinada nas suas relações com certas circunstâncias de longa data presentes na evolução da vida intelectual no país. Entre elas, destaque-se, particularmente, o fato de a literatura sobressair-se como um fator ponderável no processo vigente de comunicação de ideias e de formação de comportamentos. Em outras palavras, havia na época, e pela razão apontada, atmosfera propícia para a propaganda anarquista enveredar pelo caminho da prosa de ficção, situação esta não ignorada pelos protagonistas do episódio, esperançosos de poder tirar algum proveito ao celebrar a aliança entre a expressão literária e a propaganda revolucionária. (Luizetto, 1984, p. 4)

Arnoni Prado e Foot Hardman (1985), analisando uma seleção de contos anarquistas, ressaltam uma característica fundamental dessa literatura:

(...) o mergulho nesse universo da ficção militante nos confirmou, em relação ao conto, como de resto acontece com a arte anarquista, que ele não é propriamente um texto de autor. Ao contrário deste, que privilegia a singularização e retém o leitor na fruição estética do instante, o conto anarquista elimina a ambiguidade e integra um sistema reiterativo de propagação ideológica, ${ }^{2}$ muito embora não deva ser confundido com um mero instrumento de propaganda dirigida. Se, de um lado, fica difícil distinguir muitas vezes onde termina a doutrinação e começa a criatividade, é preciso levar em conta, de outro, que enquanto gênero ele apenas confirma o princípio geral anarquista, segundo o qual todos os homens são artistas em potencial e, nesse sentido, fazem coletivamente a arte real, compreendida como produto de um grupo social e identificado em torno de seus ideais. (p. 13)

Os mesmos autores esclarecem que, na perspectiva proudhoniana da arte em situação, não há o cultivo da arte pela arte, nascendo o texto das circunstâncias da luta travada cotidianamente. Abordando dialeticamente a relação entre vanguarda estética e vanguarda política, lembram o aperfeiçoamento

(...) das técnicas de composição da arte inspirada em temas libertários e desenvolvida por artistas militantes na França e na Espanha. No Brasil, costuma-se tomar o estilo retórico dos romances de tese anarquista (em geral escritos por intelectuais incorporados ao movimento) como uma característica extensiva a toda a literatura de cunho libertário. $\mathrm{O}$ erro maior, talvez, é considerar essa marca como um sinal de passadismo, a partir, sobretudo, do confronto com o projeto estético dos modernistas da Semana de 1922, quando o mais correto seria contrapô-la à literatura parnasiana, contra cuja temática os anarquistas se insurgiram. Acusa-se em geral a literatura anarquista de combinar a insubordinação 
política com o jargão parnasiano, esquecendo-se de que é nessa contradição que está a questão cultural a ser pensada: o processo de contaminação do universo parnasiano pelos motivos libertários, responsáveis pela recusa da atitude acadêmica comprometida com as elites intelectuais. (Arnoni Prado \& Foot Hardman, 1985, p. 15-16)

Os autores sublinham o teor crítico da literatura libertária, num país cuja literatura culta em geral descaracterizava os oprimidos e os reduzia a tipos de crônica policial. Os autores explicam a pouca importância dada pelos anarquistas à autoria das obras, vistas mais como fruto da experiência coletiva do que do refinamento estético, valendo mais o ímpeto criador do que a obra em si. Do mesmo modo, valorizavam mais as obras de autoria desconhecida, cujo autor é o espírito coletivo:

(...) só era possível a existência de indivíduos artistas porque antes deles já existia um povo artista. Daí a função pedagógica dessa arte-síntese que se interpõe entre o presente e o passado da humanidade, articulando luta e liberdade rumo à perfeita harmonia para a qual os anarquistas acreditavam estarem todos destinados. (p. 17)

Um dos aspectos mais fecundos da educação ácrata é o desenvolvimento intenso de criações teatrais, imprensa, literatura, centros de cultura, todos eles veículos pedagógicos por excelência, voltados à formação dos trabalhadores e à disseminação do ideário anarquista.

Lily Litvak, ${ }^{3}$ autora de vasta pesquisa sobre a vida cultural do anarquismo espanhol do final do século XIx e do início do século xx, conta-nos do entusiasmo apaixonado com que se educavam os militantes, vistos sempre lendo algo e discutindo em grupos. Ela afirma a importância dada pelos libertários à educação e à cultura, afirmando que "nunca, nenhum movimento outorgou à cultura tanto valor como os anarquistas" (2001, p. 275). O caráter emancipatório das práticas culturais e pedagógicas dos anarquistas baseava-se na concepção da I Internacional, ${ }^{4}$ segundo a qual a redenção dos trabalhadores deveria ser obra dos próprios trabalhadores. Desta concepção decorria a ênfase que davam ao livre arbítrio e sua fé no poder da inteligência e sensibilidade humanas, bem como à dimensão educativa e cultural que seria em grande parte responsável pela transformação social. É importante ressaltar que, para os libertários, educação, cultura e revolução são indissociáveis.

A mesma autora conta que eram lidas as obras mais notáveis do movimento operário, sendo posteriormente comentadas e criticadas. A leitura sociológica, filosófica, literária e recreativa era um hábito permanente dos militantes. Cada trabalhador socializava seus conhecimentos específicos e gerais em palestras para seus companheiros. Dessa forma, um tintureiro falava sobre química, um pintor dava noções gerais de desenho e cor, um jovem impressor ministrava curso de gramática e assim por diante. Obras em vários idiomas eram traduzidas oralmente nas reuniões, propiciando o acesso e a fruição de textos importantes, mesmo por aqueles que não dominavam outras línguas. 
Os anarquistas acreditavam firmemente na educação. O trabalhador consciente punha-se imediatamente a instruir-se. Sua crença era que a ausência de educação era o único motivo de impedimento para que outros operários compartilhassem suas crenças. Era comum a criação de uma escola em seus centros de cultura. (2001, p. 277)

Nas análises da literatura e da arte ácratas na Espanha, feitas por Litvak, são preciosas as reflexões sobre a função social da forma. A Revista Blanca publicava em suas páginas uma série de diálogos doutrinais que aclaravam, de forma anedótica, os postulados essenciais do ideário ácrata. Assim, também o leitor iria adquirindo as bases da cultura libertária: “(...) esta técnica, intimamente ligada à associação de ideias, permite que uma ideia promova outra em conexão com a original. Em outras palavras, fixa-se uma asseveração na mente e continua-se a desenvolvê-la até chegar a um postulado doutrinário determinado" (2001, p. 279).

Litvak lembra que, para os anarquistas, a educação não se limitava à infância. Eram muito importantes na vida ácrata conferências e cursos variados para trabalhadores, sendo enorme a sua sede de conhecimento, abrangendo todas as áreas da ciência e da cultura. Eles não apenas liam grandes autores, mas também produziam suas próprias obras.

O esforço cultural anarquista se vê refletido numa prodigiosa atividade editorial. Eram incontáveis os folhetos publicados pelos libertários, cujos conteúdos contemplavam desde trechos de obras clássicas do anarquismo, monografias, conferências até folhetins e novelas. Tinham geralmente uma tiragem expressiva, alcançando a marca de 10 mil exemplares e até 130 edições de uma mesma obra. A obra de Kropotkin, A conquista do pão, vendeu 50 mil exemplares a preços reduzidíssimos, no começo do século. Autores de obras científicas, como Darwin, Reclus, Haeckel e Buchner, despertavam também grande interesse, assim como tratados de astronomia e obras históricas:

(...) o esforço cultural libertário não se baseava unicamente no ideológico. A lista de suas publicações indicava sua flexibilidade e ampla esfera de interesses, na qual era abundante o material literário. A reverência à cultura em geral explica a heterogeneidade do material bibliográfico anarquista. (Litvak, 2001, p. 282)

Litvak registra o relato de um leitor pago pelos próprios operários de uma fábrica de charutos cubanos que, durante o expediente, lia para eles obras escolhidas por um comitê de trabalhadores, por quatro horas diárias. Entre os autores citados nesse depoimento estavam Galdós, D’Annunzio, Kipling, Schopenhauer, Kropotkin, Marx, Sudermann. Um trecho do depoimento:

(...) era em Havana, em pleno trópico e o público se compunha de negros, de mulatos, de nativos, de espanhóis; muitos nem sequer sabiam ler. Que obra podia emocionar tão 
intensamente aqueles homens? Hedda Gabler, o maravilhoso drama de Ibsen... Nunca desfrutou Ibsen em Cristiania de um público mais devoto e contrito. (Apud Litvak, 2001, p. 283)

Uma característica das obras publicadas e discutidas preferencialmente pelos libertários era o seu conteúdo de crítica social e rebeldia. Tal particularidade, que, entretanto, abarcava uma gama imensa de autores, seria transplantada (ainda que de modo não mecânico) para a América Latina pelos imigrantes europeus já formados na vivência cultural ácrata em seus países de origem, lembrando que, depois da Europa, a Argentina reuniu o mais importante movimento anarquista mundial. Entre os autores diletos estão Tolstoi, Ibsen, Octave Mirabeau, Zola, Balzac, Sue, além de Michelet, Ruskin, Flaubert, Diderot, Rousseau, Blasco Ibañez, Heine, Hugo, Tchekhov, Merimée, Nordeau, Kropotkin, Mella e toda a galeria de clássicos do anarquismo e do socialismo. Para tais leitores, não importava muito a ideologia dos autores, desde que houvessem escrito a favor dos oprimidos em algum momento. Litvak destaca a grande importância das bibliotecas libertárias, formadas por militantes ou em escolas e centros de cultura, entre eles a das Escolas Modernas, La Tramontana, El Productor, a Biblioteca de Ensenanza Popular, a Biblioteca Contemporánea, a Libros Rojos e as de certas casas editoriais, como a Sempere de Valencia, que, embora não estritamente anarquista, vendia ao proletariado libertário, a preços mínimos, suas edições dos clássicos de amplo espectro, dos greco-latinos a Shakespeare, Santo Agostinho, Strindberg, e tantos outros.

As publicações de livros e folhetos eram intensamente anunciadas na imprensa libertária, prática comum na Europa e nos demais países em que a cultura anarquista se implantou.

Litvak (2001) sublinha o papel de destaque na difusão cultural desempenhado por revistas como Acracia, a Revista Blanca, Ciencia Social e Natura. Nesta última, uma das mais importantes na vida intelectual anarquista, colaboraram Ricardo Mella, Clementina Jacquinet, primeira diretora da Escola Moderna, Anselmo Lorenzo, Donato Lubén. Em seu primeiro número, de outubro de 1903, há uma espécie de Declaração de Princípios, que fala do desejo de "dar a mãos cheias e repartir com a multidão desconhecida a abundante força mental", considerando que não deve haver uma pátria espiritual nem material, pois o horizonte do conhecimento humano é infinito, e a "Ciência e a Arte habitam o cume de suas mais elevadas aspirações" (2001, p. 288).

Para os anarquistas, deve haver uma unidade entre estética e vida: "a mais profunda das ciências, a mais bela das artes, será aquela que acerte ao determinar a maravilhosa mecânica da vida social, igualitária e livre". Ainda no mesmo número de Natura, na mesma Declaração, terminam pondo suas páginas a serviço de "três modos da emancipação humana: a econômico-social, a moral e a intelectual, abrindo 
seu espírito a todas as influências generosas do bem-estar geral, a todas as conquistas da inteligência, a todas as belezas da arte humana" (2001, p. 288). Cabe lembrar que essas concepções são partilhadas internacionalmente pelo movimento anarquista, portanto absorvidas no Brasil também, defrontando-se aqui e em cada país com as especificidades locais, caso da marca escravista e oligárquica da sociedade brasileira, com alto índice de analfabetismo e, na época, com uma Igreja onipresente e traços autoritários muito fortes que ainda perduram.

Todas as revistas mencionadas cumpriram papel pedagógico intencional. A Revista Blanca, explica Litvak, mantinha seu público a par das atividades artísticas e literárias europeias. Fundada por Francisco Urales, tinha por finalidade difundir os ideais libertários sem nomear-se anarquista e foi, segundo a mesma autora, a mais importante de todas as revistas do anarquismo espanhol. Instruindo e educando o povo, organizando debates, jornadas culturais e conferências, contou com a colaboração de intelectuais do porte de um Miguel de Unamuno, ao lado de nomes emblemáticos da cultura libertária espanhola como Federica Montseny, Teresa Claramunt, Anselmo Lorenzo, Ricardo Mella, Jaume Brossa, Dorado Montero, entre tantos. A revista defendeu Zola, perseguido por sua posição no caso Dreyfus, atacou o militarismo, pregou contra o alcoolismo e o tabagismo, difundiu as ideias de Tolstoi, Ibsen e outros. A maioria de seus leitores era formada pelo proletariado culto, muitas vezes autodidata.

Para os anarquistas, a educação, a cultura e, portanto, a apropriação do conhecimento pelas classes trabalhadoras sempre foram questões essenciais. Concebem a transformação social pela criação de formas igualitárias, anti-hierárquicas e desburocratizadas de organização, em sintonia com a mudança de sensibilidades, atitudes, valores e não como tomada do poder do Estado pelos partidos políticos e a constituição de uma nova classe dirigente. Em Proudhon (1809-1865), por exemplo, temos a defesa da politecnia na educação e de uma "arte-situada", destinada à difusão do ideário e à formação moral e política dos trabalhadores. Ele mantinha laços de amizade com artistas que integraram as correntes fundadoras da arte moderna na Europa, como Baudelaire, Flaubert e o pintor Gustave Courbet, configurando uma das raras confluências de vertentes avançadas da arte e da política. Mais tarde, uma repetição dessa confluência foi a aproximação de Trotsky e de setores do anarquismo ao surrealismo, todos críticos da instrumentalização da arte pelo stalinismo, o chamado "realismo socialista".

Bakunin (1814-1876) via na desigualdade de acesso ao saber e na sua apropriação uma das mais terríveis e eficientes causas da reprodução de todos os dilaceramentos sociais. Propunha a educação integral: “(...) o ensino total, tão completo como o que leva consigo o poder intelectual do século, a fim de que por cima das classes operárias não se encontre no futuro nenhuma classe que saiba mais e que, exatamente por isto, possa dominá-las e explorá-las" (Bakunin, 1989, p. 34). 
A educação integral foi incorporada pela história subsequente do anarquismo. Mas, sem dúvida, o advento do comunismo-libertário ou anarco-comunismo, no qual a atuação de Kropotkin foi marcante, conferiu uma significação fulcral às práticas culturais e pedagógicas. A predominância desta tendência no ambiente libertário mundial e brasileiro, de modo particular nas atividades do campo pedagógico-cultural, pede uma atenção maior à história dessa vertente. No período árduo que se seguiu à derrota da Comuna de Paris, o ano de 1876 concentra acontecimentos importantes para a história do anarquismo. No mês de julho, foi dissolvido o Conselho Geral da AIT e morreu Bakunin. Pouco depois, Kropotkin voltou à Europa ocidental como exilado político e estabeleceu ligações com o grupo anarquista suíço das montanhas do Jura, a Federação Jurassiana, que havia sido fundada pelos coletivistas, em 1871, em Sonvillier, após a ruptura entre marxistas e anarquistas durante a Conferência da AIT, em Londres. Tal rompimento foi definitivamente consumado em 1872, no V Congresso da AIT, em Haia, do qual os marxistas expulsaram James Guillaume (1844-1916) e Bakunin, inaugurando uma separação no interior do movimento revolucionário que até hoje não se reverteu e que conheceu episódios trágicos no século xx. Desde sua fundação, a liga Jurassiana desempenhou papel importante nas atividades intelectuais e organizacionais do anarquismo europeu, irradiando-se para outros continentes. Inicialmente coletivista, por influência de Bakunin, a Federação do Jura adotou a denominação de comunista-libertária e/ou anarco-comunista, após um processo de discussões intensas, nas quais foi decisivo o papel de Elisée Reclus, Malatesta (18531932), Carlo Cafiero (1846-1892), Covelli (1846-1915) e o próprio Kropotkin. O abandono do termo coletivismo deve-se, sobretudo, a uma compreensão distinta que coletivistas e anarco-comunistas tinham acerca da distribuição da riqueza gerada pelo trabalho numa sociedade ácrata. Para o coletivismo esta riqueza seria distribuída conforme o trabalho realizado. Discordando, Kropotkin dizia: "isso contraria o ideal da distribuição realizada conforme as necessidades" (Guérin, apud Luizetto, 1984, p. 27). Mas, para além dessa questão inicial, a fundação do anarco-comunismo constituiu um divisor de águas na história do anarquismo, conforme frisam historiadores do movimento, como Max Nettlau, Daniel Guérin e G. D. H. Cole (apud Luizetto, 1984). O teor de tal diferenciação interessa diretamente ao objetivo deste estudo. As vicissitudes sofridas com a derrota da Comuna e as perseguições constantes, o refluxo das lutas sociais, o desalento com as "oscilações das multidões", nas palavras de Elisée Reclus (apud Luizetto, 1984, p. 37), levaram os anarquistas a uma mudança de métodos e mesmo de concepções. A importância da divulgação das ideias, da transformação das consciências, foi aos poucos tomando vulto, em detrimento das táticas extremas da propaganda pela ação, da via terrorista, ainda que estas continuassem a ser aceitas por outras tendências do anarquismo. No comunismo libertário, obras seminais são publicadas, amparando teoricamente as mudanças referidas. Entre as mais densas estão Evolução, Revolução e Ideal Anarquista, de Elisée Reclus, e A Ajuda 
Mútua, de Kropotkin. A primeira interliga os processos evolutivos e revolucionários, vistos como parte integrante da vida social e cósmica, afirmando que não pode haver revolução sem evolução prévia. E, para que tais processos se expandam, é fundamental a socialização do saber. A segunda, nuclear no ideário anarco-comunista, é fruto de pesquisas do autor, que era geógrafo, nas estepes russas. Nela, Kropotkin faz uma profunda crítica às teses de Huxley, segundo as quais a competição é a base da vida humana e natural. Recusando tais assertivas, Kropotkin defende a ideia da cooperação, tida por ele como base essencial da vida, tão ou mais relevante do que a luta e a violência. É interessante lembrar a afinidade desta tese com as teorias desenvolvidas um século depois pelo prêmio Nobel chileno Humberto Maturana, para quem o amor é o cerne da evolução e da vida biológica e social. O cientificismo, integrante do espírito da época, encontrou nos anarquistas não a busca de garantir a ordem vigente, mas de construir uma alternativa a ela e de refutar os dogmas religiosos. Creio ser este um dos pontos vitais para a compreensão das práticas culturais e educacionais libertárias. As mudanças operadas no anarquismo por influência do anarcocomunismo foram responsáveis por uma grande disseminação de suas concepções, mesmo fora do círculo militante ou do meio proletário: "Kropotkin percebeu isso e, certa vez, chegou a revelar a sua satisfação pelo fato de o 'anarquismo literário' estar encontrando boa receptividade nos meios intelectuais da Europa" (Luizetto, 1984, p. 53). A persuasão, a ênfase na solidariedade, na educação, nas práticas culturais como práticas pedagógicas passaram a ser cada vez mais recorrentes no mundo ácrata. Estas dimensões eram vistas como a preparação da futura sociedade, "a garantia de que, após os atos de expropriação e de destruição do Estado, a reconstrução da vida social dar-se-ia mediante associações livremente pactuadas, sem autoridades, chefes e governos" (idem, ibid., p. 62).

O combate às duas fontes principais de qualquer tipo de autoridade, a Igreja e o Estado, percorre toda a história ácrata. Contra a Igreja porque ela aperfeiçoou os instrumentos de submissão das consciências; contra o Estado, porque usurpou o poder político oriundo do corpo social, exercendo-o em nome de uma classe ou de uma casta sobre o conjunto da sociedade, por meio de aparatos repressivos como o exército e a polícia e de recursos da "violência simbólica" como os tribunais e a escola (aos quais hoje se acrescentaram os meios de comunicação de massa, a indústria cultural).

Se o Estado, a religião e o capital fabricam incessantemente os meios de sua conservação ao produzir indivíduos submissos ou tirânicos, o anarquismo assumiu a tarefa de formar homens que possam relacionar-se com os outros como iguais na diferença, para a criação de uma sociedade na qual as diferenças não sejam transformadas em desigualdade. Reside aqui a enorme importância da luta pedagógico-cultural para o anarco-comunismo. Entretanto, a autogestão educacional é apenas um dos elementos de combate por uma sociedade libertária. A primeira experiência nessa direção foi 
a de Paul Robin (1837-1912), inspiradora de todas as demais, a partir de La Ruche, de Sébastien Faure, até a Escola Moderna de Ferrer, ecoando pelas décadas seguintes. Os princípios fulcrais da educação libertária presentes em Cempuis continuam sendo a coeducação sexual, a coeducação das classes sociais, a ausência de recompensas e castigos, a livre discussão entre professores e alunos, a formação do espírito crítico, a prática da observação e do ensino racional, a convivência junto à natureza, a educação estética.

Nascido na França, em família burguesa, Robin teve uma educação refinada. Desde cedo, interessou-se pelo ensino, chegando a ingressar na Escola Normal Superior. Entretanto, abandonou o magistério por não suportar a atmosfera sufocante do ensino sob o II Império. Na Bélgica, participou da fundação de uma associação positivista e de cursos noturnos para filhos de operários. Filiou-se à seção da AIT de Bruxelas e assumiu a redação do jornal de tendência proudhoniana La Liberté. Foi expulso da Bélgica por razões políticas, depois de se casar com a filha do socialista Delasalle. Passou por várias prisões européias até refugiar-se em Londres, onde foi indicado por Marx para o Conselho Geral da Internacional. Robin opôs-se às teses autoritárias, sendo excluído do Conselho Geral. Adotou as teses de Bakunin e passou a frequentar os círculos jurassianos, ao lado de Kropotkin e dos irmãos Reclus. As primeiras experiências educacionais de Robin foram como diretor de uma escola profissional em Chambéry e da Escola Normal. Em 1879 tornou-se inspetor primário em Blois. Nessa ocasião que ele escreveu: "Toda a educação que não tenda a fazer um pensador, um trabalhador, um ser inteligente e um ser ativo, é uma educação incompleta e estéril" (Robin, apud Moriyón, 1989, p. 101).

O inspetor Robin, para escândalo de muitos e para aprovação de alguns, reestruturou os programas nessas escolas e colocou lado a lado meninos e meninas. A partir de 1880, quando foi nomeado diretor do orfanato Gabriel Prévost, em Cempuis, buscou realizar seus princípios pedagógicos fundados na liberdade, na confiança e na coeducação sexual. Um ex-aluno seu registrou o seguinte depoimento: "O ensino não era politeísta nem monoteísta, nem deísta, nem panteísta, nem ateu; era pura e simplesmente humano"(idem, ibid., p. 102).

As pesquisas divulgadas pelos estudos clássicos do anarquismo sobre a experiência pioneira de Cempuis contam da felicidade das crianças ali e também em Mers-les-Bains, onde Robin adquiriu um terreno e construiu uma casa para acolher os jovens órfãos de Cempuis durante o verão. O êxito da pedagogia de Robin despertou a ira conservadora da Igreja e dos poderes constituídos e culminou com a sua demissão, em 1894.

A partir de então, o educador consagrou-se ao movimento neomalthusiano, defendendo a necessidade de limitar os nascimentos. Publicou um prospecto intitulado 
A questão sexual e tentou, em vão, mobilizar o ambiente anarquista para a sua ideia do "bom nascimento".

Todos os grandes estudiosos da pedagogia libertária, como Dommanget (1972), Palácios (1981), Tomasi (1988) e Raynaud e Ambauves (1978), são unânimes em afirmar que a prática-teórica de Robin no Orfanato de Cempuis foi o nascedouro da pedagogia libertária. Admirador de Rousseau e do cientificismo, Robin adotou do anarco-comunismo pontos fundamentais como o pacifismo, o internacionalismo, o apoio à emancipação feminina, o ensino integral. Aos vinte anos registrou a seguinte reflexão:

Que fiz eu para ser melhor tratado do que um proletário? Para conhecer as artes e as ciências? Não merecem todos os trabalhadores como eu desfrutar das alegrias intelectuais? (...) O dever sagrado, o primeiro de todos é trabalhar sem descanso para acabar com as misérias que lhes aplastram. (apud Tomasi, 1988, p. 174)

No boletim do Orfanato, de 1890, ele escreveu:

A educação integral, sem ter a pretensão de fazer de todos cientistas, (...) tem a intenção de propiciar o nascimento e desenvolvimento de todas as faculdades da criança, para incutir-lhe somente ideias exatas. Porém, depois de ter oferecido a todos esta base indispensável e objetiva, deixa a cada um a tarefa de completar seu desenvolvimento segundo as circunstâncias, as necessidades, as iniciativas pessoais, e de aproximar-se do saber e do ofício só naquelas áreas das quais depende a satisfação de suas necessidades físicas e morais. (Idem, ibid., p. 175)

Durante os 14 anos em que dirigiu Cempuis, Robin institucionalizou a liberdade da criança, possibilitando a expansão de suas múltiplas potencialidades. Integrando trabalho manual e intelectual em aulas ao ar livre, junto à natureza, com a inovação das colônias de férias no litoral, visava o desenvolvimento moral, praticava a coeducação sexual, a formação científica e as atividades artísticas. Uma das dimensões mais belas da pedagogia de Robin foi a ênfase na educação musical. Continuando sua obra, Sebastien Faure (1858-1942), em La Ruche, instituiu a imprensa na escola e editou um opúsculo de canções, coros e comédias para crianças. Robin tinha repugnância pelos exames, notas e concursos. A relação com os alunos era desenvolvida sem hierarquias e a virtude mais valorizada era a solidariedade, por sua contribuição responsável à vida coletiva. Sua obra em Cempuis foi irradiadora de uma formação de educadores que muito contribuiriam para a melhoria das práticas e concepções da pedagogia contemporânea, a começar por Sebastien Faure (18581942) e Francisco Ferrer (1849-1909), chegando a Célestin Freinet (1896-1966). Perseguido pela Igreja e pelos poderes locais, Robin foi compelido a abandonar Cempuis. Todas as crianças que por lá passaram guardaram uma recordação permanente e obtiveram resultados escolares excepcionais em relação ao período anterior à chegada de Robin, além de melhoras comprovadas na saúde. Para Dommanget, Robin foi: 
(...) dotado da mais extraordinária vocação pedagógica, de uma inteligência superior e de uma alma de apóstolo (...) é o educador no sentido mais profundo da palavra, uma das maiores figuras, senão a maior, da pedagogia socialista, e uma figura esquecida. (Dommanget, 1972, p. 349)

Talvez a maior síntese das práticas e concepções da educação libertária tenha sido realizada por Francisco Ferrer, criador das Escolas Racionalistas ou Modernas, na Espanha, a partir de 1901 até seu assassinato político em 1909: “(...) Ferrer recebe influências de toda a tradição libertária, de Godwin (1756-1836) a Kropotkin, passando pelos socialistas utópicos, Stirner (1806-1856), Bakunin, etc., tendo se relacionado com alguns deles em Paris", sublinha Palácios (1981, p. 159). As bases da pedagogia de Ferrer são a coeducação de sexos e de classes, a ausência de recompensas e castigos, a educação integral, o ensino fundado na ciência e não em misticismos ou noções religiosas, a formação permanente do caráter, o cultivo da vontade, a harmonia corpo-intelecto-moralidade, sempre com base nos exemplos e na grande lei natural da solidariedade; a educação infantil deveria buscar métodos adaptados à psicologia da criança. Ferrer foi amigo próximo de Kropotkin e de Robin, entre outras personalidades do mundo libertário. Sua obra, de importância inestimável para a emancipação humana, incluía uma casa editorial, que publicava mensalmente os Boletins das Escolas, entre 1901 e 1906. A influência de Ferrer disseminou-se por vários continentes, chegando até a Europa do leste, onde Nestor Makhno chegou a fundar uma escola racionalista (Raynaud \& Ambauves, 1978). Também no Brasil foram criadas inúmeras escolas inspiradas nas Escolas Modernas. Segundo Edgar Rodrigues (1992), entre 1895 e 1925 foram criadas no Brasil, e não só nas regiões mais industrializadas, 40 escolas libertárias. No campo educacional, os anarquistas projetavam criar outro sistema de ensino, oposto em tudo ao privado e ao estatal. Tal projeto foi inviabilizado por vários fatores, entre os quais a repressão do Estado, as políticas da III Internacional e as alterações profundas no quadro político-econômico internacional, com a II Guerra Mundial.

A experiência das Escolas Racionalistas foi profundamente articulada às práticas culturais anarquistas da época, referidas neste artigo. Tal organicidade é, aliás, uma característica geral do movimento ácrata.

A crítica anarquista aos Estados e aos governos não faz exceção sequer aos governos representativos, ao mostrar que as leis chamadas democráticas obrigam as minorias a se submeterem às maiorias, os partidos impõem uma disciplina coercitiva e criam laços artificiais entre seus membros e o sufrágio universal é, nas palavras de Bakunin, "o meio mais adequado para fazer com que a massa colabore na construção de sua própria prisão" (1978, p. 52). O mesmo autor lembra que a chamada liberdade de imprensa e de associação é apenas respeitada quando não incomoda muito aos que governam. Outra dimensão fundamental do ideário anarquista é o 
internacionalismo que, entretanto, não exclui o amor espontâneo dos homens por seu país, mas impede que ele degenere em xenofobia e guerras nacionalistas. Para os libertários, a ideia de pátria é separada da de Estado.

Grande parte da tradição anarquista é herdeira da concepção rousseauista de uma bondade essencial da natureza humana que teria sido deformada pelas instituições sociais calcadas na exploração e na opressão. Surge daí a convicção de que é possível desenvolver uma ética fundada na liberdade, na dignidade e no valor do indivíduo como consequência de leis ditadas pela consciência e desenvolvidas em instituições libertárias e não por fontes coercitivas externas e autoritárias. Assim, lemos em Kropotkin (1987, p. 103) a seguinte reflexão, tão atual:

De ano a ano, milhares de crianças crescem na sujeira moral e material de nossas cidades
entre uma população desmoralizada pela vida diária, caracterizada pelo desemprego e
pela miséria junto ao luxo e ao vício que inundam nossas grandes povoações. Não sabem
o que é a casa paterna, sua casa hoje é rústica, amanhã é a própria rua. Entram na vida
sem ter feito um emprego razoável de suas jovens forças. (...) Quando vemos crescer deste
modo a população infantil das grandes cidades só nos admira uma coisa: que tão poucos
daqueles meninos se tornem assassinos e ladrões. O que surpreende é a profundidade
dos sentimentos sociais da humanidade de nosso século, a tendência ao bem que reina no
beco mais asqueroso. Sem isso o número dos que declaram guerra às instituições sociais
seria muito maior. Sem essa honradez básica, sem essa aversão à violência, não ficaria
pedra sobre pedra dos suntuosos palácios de nossas cidades.

A possibilidade de uma convivência social em comunidades livres e igualitárias, unidas em federações nacionais e internacionais, autogeridas, onde qualquer grupo - inclusive a família - baseia-se no espontâneo e revogável consentimento de cada um dos membros, constitui o núcleo das concepções societárias anarquistas. No que diz respeito à questão da violência como instrumento político, Tina Tomasi (1988, p. 9) lembra que

(...) os anarquistas, divididos no plano doutrinal e histórico em individualistas e societários, diferem entre si no que se refere aos tempos e aos meios mais adequados para mudar a vida associativa; há os que indicam a via lenta e pacífica da persuasão e os que preferem a via rápida da ação revolucionária. De todas as formas, em contraposição à opinião corrente, o ideal anarquista que se configura nos melhores teóricos, embora se expresse em linguagem agressiva, recusa a violência pelo que ela carrega de coerção ou apenas a admite quando constitui a única via para acabar com instituições injustas e cruéis. $\mathrm{Na}$ realidade o movimento anarquista teve formações militares organizadas apenas durante a Guerra Civil Espanhola e os atentados políticos, mesmo quando obra de anarquistas, longe de ser um fenômeno de vastas proporções, diminuíram notavelmente com o crescimento do anarcosindicalismo.

A harmoniosa articulação de educação e cultura marca a tradição libertária, que define o campo da educação como aquele que possibilita o acesso à cultura aos 
sujeitos sociais, tornando-os capazes não só de fruí-la, mas de produzi-la, recriando-se a si mesmos e ao mundo.

A paixão pedagógica dos anarquistas, sua aplicada dedicação ao ensino e às outras atividades culturais, a criação de uma prática teórica simultaneamente social e política, educacional e cultural, inseparável da forma de suas lutas, são ângulos ainda pouco explorados pelos estudiosos da educação e constituem pontos importantes para a compreensão crítica de nossas próprias dificuldades como educadores.

\section{Notas}

1. A experiência das Escolas Modernas em São Paulo - que neste trabalho não será analisada - é objeto de pesquisa coletiva do Centro de Memória da Faculdade de Educação da Universidade de São Paulo, onde se encontra o acervo do educador anarquista João Penteado, fundador daquelas Escolas nas primeiras décadas do século xx. Esta pesquisa tem o financiamento do CNPq.

2. Este termo aqui assume o significado comum de corpo de ideias, ideário.

3. Tradução dos textos de Lily Litvak e Tina Tomasi: Doris Accioly e Silva.

4. Fundada em 1864, na Inglaterra, foi a primeira organização internacional dos trabalhadores e visava o fortalecimento mundial e autogestionário de suas lutas, com base nas práticas de solidariedade e de autonomia, a partir da crítica do Estado, dos partidos políticos e da representação parlamentar. Sua sigla é AIT (Associação Internacional dos Trabalhadores) e ela se extinguiu em 1875/1876. No V Congresso, em 1872, houve a ruptura entre marxistas e anarquistas, culminando com a expulsão desses últimos por aqueles. A questão central que motivou tal separação foi a profunda divergência dos dois grupos acerca dos meios de transformação social. Os anarquistas defendiam a abolição imediata do Estado no processo revolucionário, enquanto os marxistas achavam necessário manter o Estado nos primeiros tempos da revolução para só posteriormente eliminá-lo. Tal discordância persiste até hoje.

\section{Referências}

ARNONI PRADO, A.; FOOT HARDMAN, F. Contos Anarquistas. São Paulo: Brasiliense, 1985.

BAKUNIN, M. Dios y el Estado. Barcelona: Jucar, 1978.

BAKUNIN, M. A educação integral. In: Morirón, F.G. (Org.) Educação libertária. Porto Alegre: Artes Médicas, 1989.

DOMMANGET, M. Los grandes socialistas y la educación: de Platón a Lenin. Madrid: Fragua, 1972.

FERRER Y GUARDIA, F. La escuela moderna. Madrid: Zero, 1978.

FOOT HARDMAN, F. Nem pátria, nem patrão! São Paulo: UNesP, 2002. 
GEERTZ, C. A interpretação das culturas. Rio de janeiro: Zahar, 1978.

HELL, V. A ideia de cultura. São Paulo: Martins Fontes, 1989.

HISTÓRIA do anarquismo. Trad. de Plínio Augusto Coelho. São Paulo: Imaginário, 2008.

KROPOTKIN, P. Textos Escolhidos. Porto Alegre: LPM, 1987. (Organização e introdução de Maurício Tragtenberg).

LITVAK, L. Musa libertaria: arte, literatura y vida cultural del anarquismo español. Madrid: Fundación Anselmo Lorenzo, 2001.

LUIZETTO, F.V. Presença do anarquismo no Brasil: um estudo dos episódios literário e educacional - 1900/1920. 1984. Tese (Doutorado) - Faculdade de Filosofia Letras e Ciências Humanas, Universidade de São Paulo, São Paulo.

PALACIOS, J. La cuestión escolar. Barcelona: Laia, 1981.

RAYNAUD, J.M.; AMBAUVES, G. L'education libertaire. Paris: Spartacus, 1978.

RODRIGUES, E. O anarquismo na escola, no teatro e na poesia. Rio de Janeiro: Archiamé, 1992.

TOMASI, T. Breviario del pensamiento educativo libertario. Cali: Carvajal, 1988.

WHITAKER, D.C.A.; BEZZON, L.C. A cultura e o ecossistema: reflexões a partir de um diálogo. Campinas: Alínea, 2006.

WILLIAMS, R. Palavras-chave: um vocabulário de cultura e sociedade. São Paulo: Boitempo, 2007.

Recebido em abril de 2008.

Aprovado em dezembro de 2008. 